\title{
CORRIGENDUM
}

\section{The BH3-only member Noxa causes apoptosis in melanoma cells by multiple pathways}

M Hassan, A Alaoui, O Feyen, A Mirmohammadsadegh, F Essmann, A Tannapfel, E Gulbins, K Schulze-Osthoff and UR Hengge

Oncogene (2011) 30, 2086; doi:10.1038/onc.2011.64

Correction to: Oncogene (2008) 27, 4557-4568; doi:10.1038/onc.2008.90; published online 14 April 2008

Since the publication of the above paper, the authors found inadvertent errors and mislabelings in

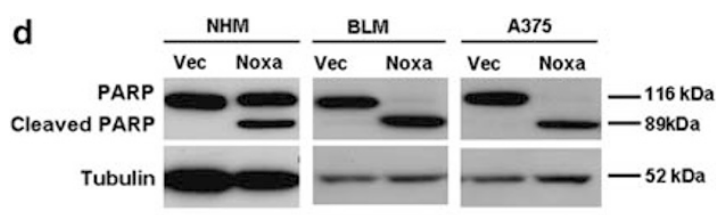

g

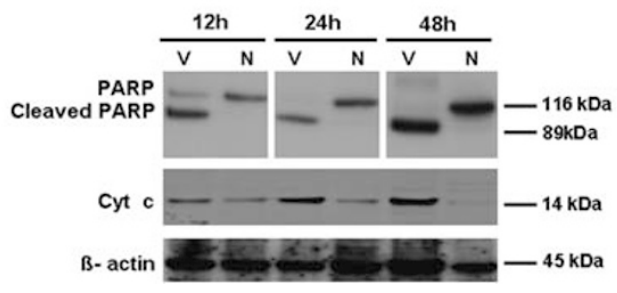

Figure 1

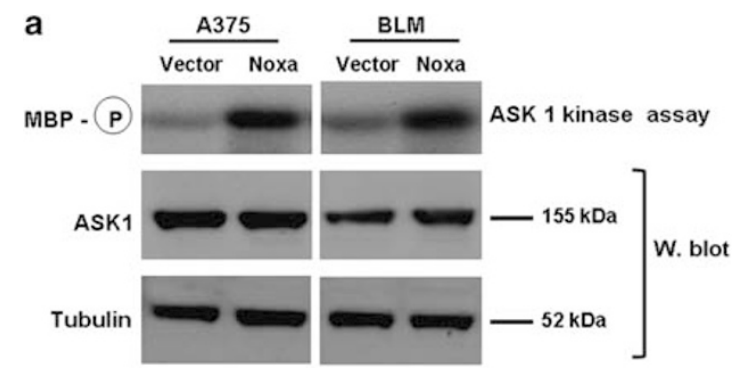

Figure 4
Figures $1 \mathrm{~d}, \mathrm{~g}, 4 \mathrm{a}$ and $5 \mathrm{c}$. The correct version of the figures is given here. The correction does not affect the validity of our data and does not limit the conclusions drawn in the paper. The authors apologize for this mistake.

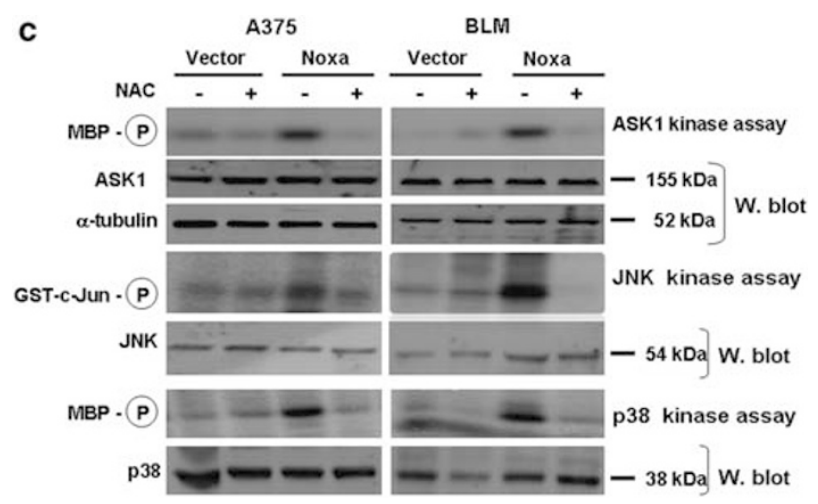

Figure 5 